\title{
A EXPANSÃO URBANA SOBRE MANGUEZAIS NO MUNICÍPIO DE PARANAGUÁ: O CASO DOS BAIRROS JARDIM IGUAÇU E VILA MARINHO
}

\author{
Carlos Eduardo da Silva ${ }^{1}$ \\ Emerson Luis Tonetti ${ }^{2}$ \\ Allan Paul Krelling ${ }^{3}$
}

\begin{abstract}
RESUMO
Este estudo discute a perda das áreas de manguezais, no município de Paranaguá no litoral do Paraná. Os textos revisados demonstraram que o crescimento populacional e o processo de expansão da área urbana sofreram influência dos ciclos econômicos do Estado do Paraná e da presença do Porto de Paranaguá, culminando em um crescimento acelerado e desordenado horizontalmente, afetando os ambientes frágeis, como as áreas de manguezais. Essas áreas, segundo a legislação ambiental, são consideradas de Preservação Permanente. A orientação do Plano Diretor para ordenar o território e encaminhar os rumos da expansão do espaço urbano, e suprir a demanda de novas habitações, seria o adensamento populacional por verticalização das edificações. Contudo, o município de Paranaguá ainda não conseguiu implantar tal adensamento. Nota-se através do estudo de caso, que o crescimento urbano populacional vem ocorrendo e expandindo-se horizontalmente sobre os manguezais, de forma irregular e desordenada.
\end{abstract}

PALAVRAS-CHAVE: Paranaguá. Manguezal. Expansão urbana.

\section{URBAN EXPANSION OVER MANGROVE FORESTS IN PARANAGUÁ: A CASE-STUDY OF TWO NEIGBOURHOODS JARDIM IGUAÇU AND VILA MARINHO}

\section{ABSTRACT}

The aim of the present research is discussing losses of mangrove forests in urban areas due to Paranaguá'surban expansion, the major city of Parana's Coastal area. Literature reviewed points out

\footnotetext{
${ }^{1}$ Licenciado em Letras, Especialista em Gestão Ambiental, IAP-Paranaguá. carloses@iap.pr.gov.br

${ }^{2}$ Biolólogo, Doutor em Geografia, IFPR-Paranaguá. emerson.tonetti@ifpr.edu.br

${ }^{3}$ Oceanógrafo, Mestre em Gestão Costeira, IFPR-Paranaguá. allan.krelling@ifpr.edu.br
} 
Revista Nacional de

Gerenciamento de Cidades

that population growth and urban expansion of Paranaguá were influenced by both economic cycles and presence of a Port in the city (Paranaguá's Port). Such aspects drove the city of Paranaguá to a rapid economic growth and to an unordered horizontal urban expansion. As a result, fragile environments such as mangrove forests of the city, which are environmental protected areas according to the Brazilian laws, were affected or lost. Paranaguá's Master Plan, created in 2007, orientates that urban expansion must be conducted through verticalization, in order to attend the demand for new habitations. However, as observed in the case studies of Jardim Iguaçu and Vila Marinho, such strategy hasn't been fully implemented yet. Based on those cases, it is possible to conclude that urban population keeps growing and the urban expansion is still happening horizontally in Paranaguá, what implies in mangrove forests suppression and impacts over environmental protected areas of the city.

KEY-WORDS: Paranaguá. Mangrove Forest. Urban expansion.

\title{
LA EXPANSIÓN URBANA SOBRE MANGLARES EN LA CIUDAD DE PARANAGUÁ: EL CASO DE LOS BARRIOS JARDIM IGUAÇU E VILA MARINHO
}

\begin{abstract}
RESUMEN
Este estudio analiza la pérdida de zonas de manglares en la ciudad de Paranaguá, en la costa del Estado de Paraná, Brasil. La literatura revisada muestra que el crecimiento de la población y el proceso de expansión urbana se vieron influidos por el ciclo económico del Estado de Paraná y la presencia del Puerto de Paranaguá, que culminó en un crecimiento rápido e incontrolado horizontal, que afecta a los ambientes frágiles, como las zonas de manglares. Estas áreas, de acuerdo con la legislación ambiental brasileña, son consideradas de preservación permanente. La orientación del plan director para la ordenación del territorio y para la expansión del espacio urbano, satisfaciendo la demanda por nuevas viviendas, sería por medio de la densificación utilizando la verticalización urbana. Todavía, el municipio de Paranaguá no ha implementado esta estrategia. Se observa a través del estudio de casos, que el crecimiento urbano de la población se está produciendo y expandiendose horizontalmente por sobre los manglares, de una manera irregular y desordenada.
\end{abstract}

PALABRAS-CLAVE Paranaguá. Manglares. Expansión Urbana.

\section{INTRODUÇÃO}

O crescimento populacional e a má gestão do uso do solo, levam ao aumento da susceptibilidade de intervenções antrópicas, degradação e ocupação inadequada de ambientes frágeis e de Áreas de Preservação Permanente, como os manguezais. 
Revista Nacional de

Gerenciamento de Cidades

Os manguezais ocorrem associados às margens de baías, enseadas, barras, desembocaduras de rios, lagunas e reentrâncias costeiras, onde haja encontro de águas de rios com a do mar, ou diretamente expostos á linha da costa. A ocupação irregular e desordenada sobre essas áreas de manguezais, reduz, não apenas a sua ocorrência, mas também as funções ambientais desempenhadas por esse tipo de ambiente.

No Paraná, os manguezais, estão presentes na baia de Guaratuba e no Complexo Estuarino de Paranaguá. Em ambos os ambientes a ocupação irregular e desordenada sobre as áreas de manguezais tem sido preocupante.

Diante deste contexto, o presente artigo pretende caracterizar a perda das áreas de Formação Pioneiras sob Influência Fluviomarinha (manguezal), no município de Paranaguá, no litoral do Paraná, em face (i) das restrições legais incidentes sobre esse ambiente, (ii) dos aspectos históricos da expansão urbana horizontal e do crescimento populacional e (iii) das orientações do Plano Diretor Municipal para reduzir a demanda por novos espaços urbanos. Utilizou-se como estudos de caso os bairros Jardim Iguaçu e Vila Marinho, no município de Paranaguá.

\section{DESENVOLVIMENTO}

\subsection{RESTRIÇÕES LEGAIS INCIDENTES SOBRE O MANGUEZAL}

O ecossistema manguezal possui diversas normativas que dão suporte a sua proteção. O Código Florestal Lei $n^{\circ} 12651 / 12$, versa sobre a proteção da vegetação nativa, inclusive os manguezais em toda sua extensão (Art 4, Inc. VII); e preceitua in verbis (Art.11-A -inciso II) a "salvaguarda da absoluta integridade dos manguezais arbustivos e dos processos ecológicos essênciais a eles associados, bem como da sua produtividade biológica e condição de berçário de recursos pesqueiros" (BRASIL, 2012). 
Revista Nacional de

Gerenciamento de Cidades

Além do referido diploma legal, também a Resolução do Conselho Nacional do Meio Ambiente (CONAMA) n04/1985 dispõe que o manguezal é considerado Reserva Ecológica (conforme seu Art. $3^{\circ}, \mathrm{VIII}$ ) (BRASIL, 1985), enquanto a Lei 7661/98, que institui o Plano de Gerenciamento Costeiro, em seu Art. $3^{\circ}$, inciso I, impõe prioridade á sua conservação e proteção, em caso de zoneamento, entre outros, aos manguezais (BRASIL, 1998a).

Outrossim, o Art.3ํ. X da Resolução CONAMA n 303/2002 (BRASIL, 2002) prescreve que as áreas situadas em manguezal são de Preservação Permanente, em toda sua extensão.

De acordo com a Lei $n^{\circ} 9605 / 98$ que contém as sanções penais e administrativas derivadas de condutas e atividades lesivas ao meio ambiente, em seu Art. 38 veta terminantemente "destruir ou danificar floresta considerada de Preservação Permanente (no caso em estudo mangue), mesmo que em formação, ou utilizá-la com infringência das normas de proteção." (BRASIL, 1998b).

Além de serem consideradas APPs, os manguezais são terrenos da União, área essa que, segundo o Art.11 do Decreto n²4.643 de 10 de julho de 1934 , qualifica o terreno de marinha como bem Dominical, o que significa que o povo não tem livre acesso a eles, e que os terrenos da União são identificados a partir da média das marés altas, chamada de preamar-média (BRASIL, 1934).

No Plano Diretor de Desenvolvimento Integrado de Paranaguá (PDDIP), elaborado em 2007, os manguezais e outras áreas são enquadrados na Zona Restrita á Ocupação - ZRO, (áreas de Preservação Permanente - manguezais). Nestes locais, não está previsto o fornecimento legal de água potável e luz elétrica, assim como outras infra-estruturas, que conforme o Art. 57 da Lei Complementar n062/07 caracteriza-se pela existência de áreas com características naturais que exigem tratamento especial devido a seu potencial paisagístico e ambiental, e tem por objetivos, segundo o Art.58, "impedir a ocupação de forma a assegurar a qualidade de vida da população, preservar os manguezais, as margens e as nascentes dos canais de drenagem." (PARANAGUÁ, 2007, LC 62). 


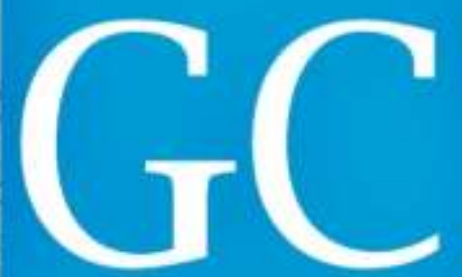

Revista Nacional de

Gerenciamento de Cidades

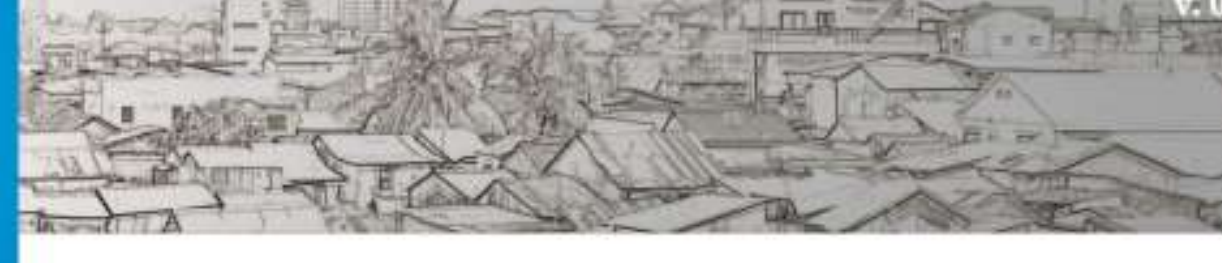

\subsection{ASPECTOS HISTÓRICOS DA EXPANSÃO URBANA E DO CRESCIMENTO POPULACIONAL NO MUNICÍPIO DE PARANAGUÁ}

A evolução da ocupação de Paranaguá está relacionada a uma série de fatores, em virtude de Paranaguá ser o local de início da colonização do território paranaense, sendo influenciado pelos ciclos econômicos do Estado do Paraná, assim como, pela presença do Porto Dom Pedro II, ou Porto de Paranaguá, como é mais conhecido. Em função disso, a cidade de Paranaguá tem apresentado um acentuado crescimento urbano horizontal, conforme pode ser visualizado na Figura 1.

Figura 1: Evolução da ocupação urbana do município de Paranaguá

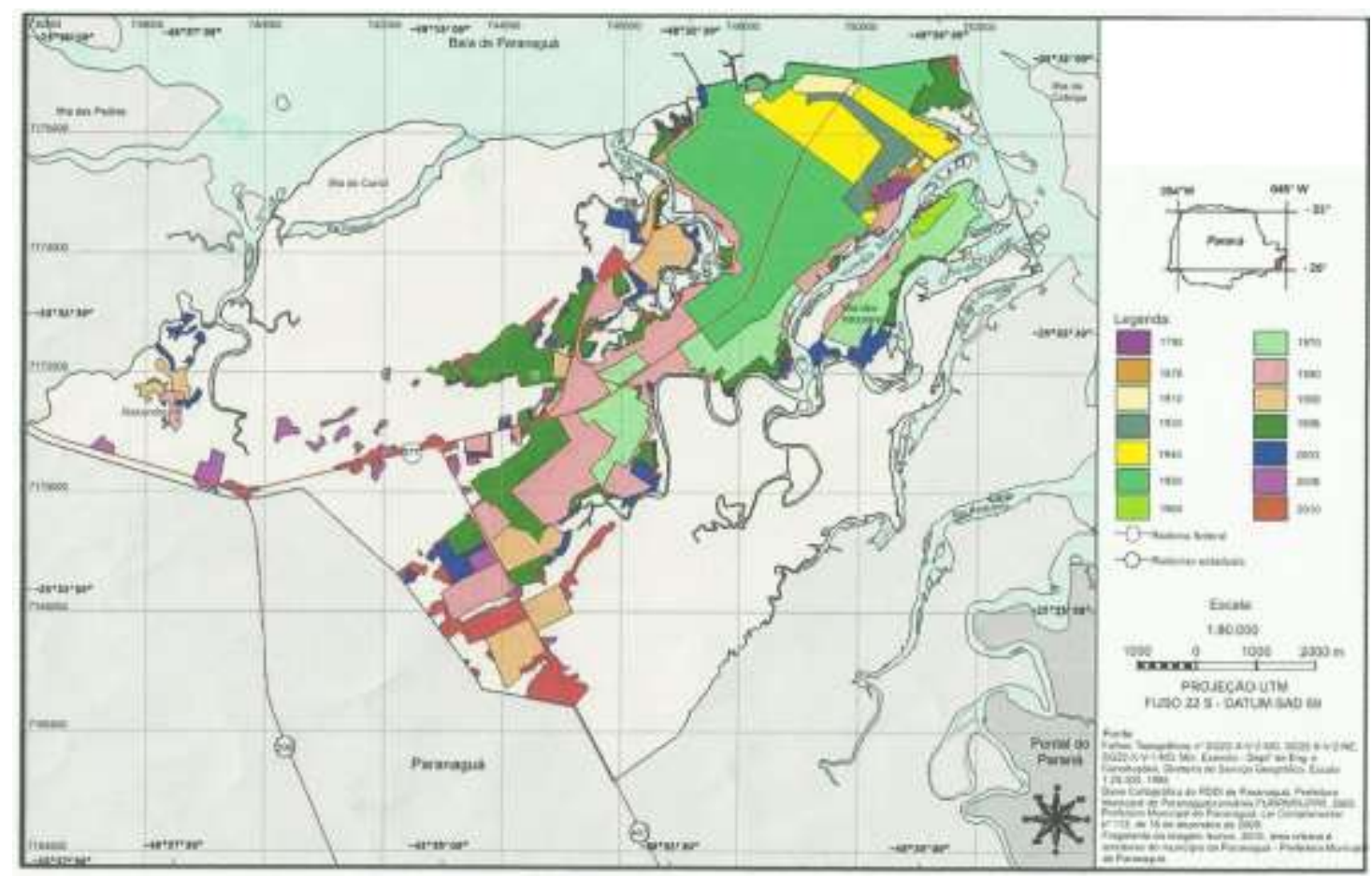

Fonte: Ricobom (2012, p.161) 
Revista Nacional de

Gerenciamento de Cidades

Inicialmente a ocupação urbana se dá no leste da cidade, nas imediações do antigo porto, que se encontrava nas margens do Rio Itiberê. A inauguração do Porto Dom Pedro II, em 1873, no Bairro Rocio, é um marco do avanço da expansão urbana para a região norte do município. Todavia, é a partir do início do século XX que a área urbanizada se destaca na paisagem na planície litorânea do município, impulsionada especialmente pelas ligações, ferroviária e rodoviária, do Norte do estado com o Porto de Paranaguá e também pelo estabelecimento dos grandes armazéns de café nas proximidades do porto Dom Pedro II (Figura 1) (SANTOS, 1952; TRAMUJAS, 1996).

Observando as características populacionais do mesmo período, Ricobom (2012), revendo as estatísticas históricas de Paranaguá, observou que em 1900 o município contava com uma população de 8.000 habitantes, nos 32 quarteirões que formava a área urbana em um total de 30.000 habitantes no município, quando ainda faziam parte de Paranaguá os atuais municípios de Matinhos e Pontal do Paraná ${ }^{4}$.

$\mathrm{Na}$ década de 50 , com o aumento da produção de café e consequente movimentação de navios novas populações do campo e de outras localidades, intensificam a expansão urbana horizontal do município, ocasionando uma ocupação mais expressiva da cidade no sentido noroeste, ocorrendo desiquilíbrios sociais e espacias na região (SANTOS, 1952; TRAMUJAS, 1996).

Em 1967, a inauguração da BR 277 ligando Paranaguá a Curitiba e esta, a Foz do Iguaçu, fez com que se iniciasse a diversificação de exportações via Porto de Paranaguá, uma vez que a rodovia conectou diversas regiões produtoras de cereaisao Porto de Paranaguá (APPA, 1994).

Entre as décadas de 1970 a 1990, armazéns e silos foram construídos nas imediações do porto, havendo também sua ampliação e remodelagem para atender a demanda da exportação de grãos,tornando assim, na ocasião, o porto de

\footnotetext{
${ }^{4}$ Estes municípios, desmembraram-se de Paranaguá nas décadas de 1960 e 1990, respectivamente.
} 
Revista Nacional de

Gerenciamento de Cidades

Paranaguá o maior exportador do país. Neste mesmo período, os serviços de mãode-obra passam a ser substituídos por máquinas, havendo a redução de empregos, aumentando os problemas sociais na cidade e face a remodelagem do espaço urbano em seu entorno, iniciaram-se então novos setores habitacionais, isto é, surgiram novos bairros, como: Vila Guarani, Rocio, Jardim Samambaia, Primavera, São Vicente e Divinéia. Nesse período ampliou-se também a expansão urbana às margens da BR-277 e no entorno da PR-407, onde intensificou-se especialmente a ocupação de Áreas de Preservação Permanente, como os manguezais das margens dos Rios Itiberê e Emboguaçu (CANEPARO, 1999).

Hoje, o crescimento urbano horizontal de Paranaguá é limitado por barreiras naturais sendo que o centro da cidade está situado entre as margens do rio ltiberê no lado Leste, do rio Emboguaçu no lado Oeste, e da Baia de Paranaguá com o cais do porto e toda a sua infraestrutura na parte Norte (Figura 1). Com essas barreiras naturais limitando a expansão urbana, apenas as partes Sudoeste(seguindo a direção da rodovia BR-277) e Sul, (na direção da PR 407-Estrada das Praias), representam áreas passíveis de crescimento urbano horizontal. Soma-se a essas limitações geográficas para o crescimento urbano as limitações impostas pela legislação ambiental, que estabelece restrições á ocupação dos ecossistemas de alta fragilidade ambiental dessas áreas (PARANAGUÁ, 2007, LC 60). Considerando todas essas limitações, atualmente apenas $4,9 \%$ da área total do município está disponível para antropização (PDDIP, 2007).

Mesmo com essas limitações, observa-se que Paranaguá foi o município do litoral paranaense que apresentou, entre as décadas de 1950 até 2010, um crescimento populacional acelerado, passando de 24.638 habitantes em 1950, para 140.469 habitantes em 2010, ficando com uma taxa de urbanização de 96,38\% (IBGE, 2011).

Grande parte desse aumento populacional é decorrente da imigração ocorrida no município no referido período. Estades (2003) destaca que uma das causas do movimento migratório em Paranaguá foi a expectativa gerada pela 


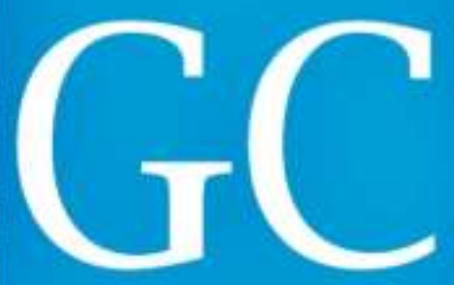

Revista Nacional de

Gerenciamento de Cidades

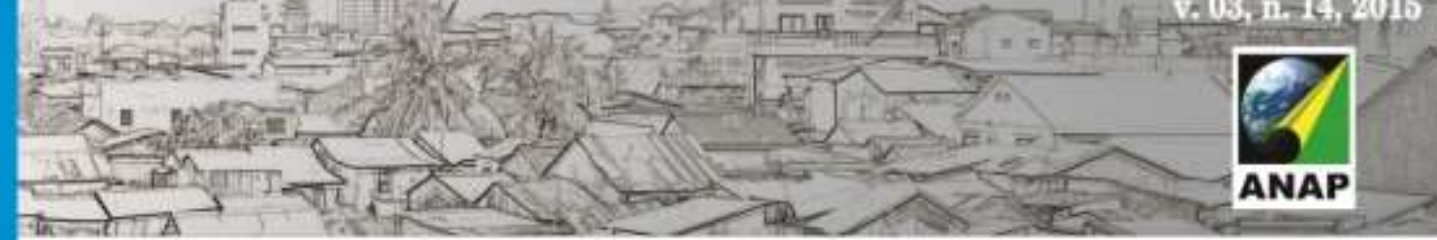

expansão das atividades portuárias. Provavelmente, os valores econômicos divulgados com as sucessivas quebras de recordes de exportação apresentados anualmente pela gestão do Porto de Paranaguá, também contribuíram com o aumento dos índices migratórios do município.

Godoy et al. (1998) entendem que esse crescimento tem gerado algumas situações de tensão na cidade, tais como: ocupação de Áreas de Preservação Permanente, saneamento básico ineficiente, problemas de prestação de serviços (escolas, sistema viário e assistência á saúde), degradação ambiental e problemas sociais.

Neste sentido, o Plano Diretor de Paranaguá apresenta informações que demonstram extensas áreas com ocupações irregulares, conforme demonstra a Figura 2.

Figura 2: Mapa da distribuição das ocupações irregulares do Município de Paranaguá
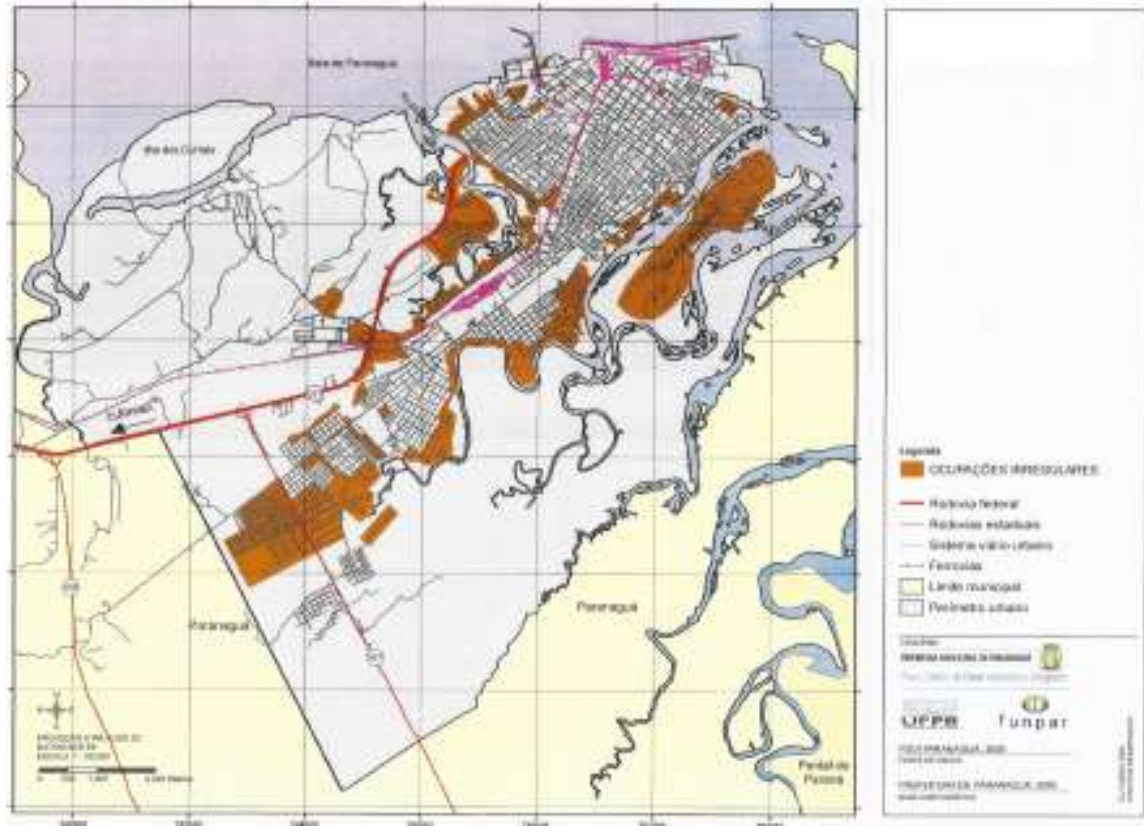

Fonte: Prefeitura Municipal de Paranaguá (2005) 
Revista Nacional de

Gerenciamento de Cidades

Desta forma, em Paranaguá, o processo de ocupação, historicamente, promove a expansão horizontal da área urbanizada sobre a planície costeira, ocupando manguezais, restingas e margens de rios, onde os ambientes urbanos crescem ocupando, com edificações e outras construções, áreas que desempenham serviços ecológicos importantes na manutenção e melhoria da saúde do cidadão e da qualidade do ambiente urbanizado (TONETTI; NUCCI; VALASKI, 2012).

Destacam-se, nesse processo, os bairros Costeira e Rocio (esses nas imediações do porto), Vila Guarani, Beira Rio, Padre Jackson, Vila Santa Helena, Emboguaçu, Figueira, Ponta do Caju, Vila São Vicente, Jardim América, Jardim Guaraituba, Vila Primavera, Porto dos Padres, Jardim Araça, Ilha dos Valadares, Parque São João, Santos Dumont, Itiberê, Jardim Iguaçu e Vila Marinho, com ocupações desordenadas e irregulares.

\subsection{AS ORIENTAÇÕES DO PLANO DIRETOR PARA A EXPANSÃO URBANA DO MUNICÍPIO DE PARANAGUÁ}

Os Planos Diretores Municipais são instrumentos públicos que devem definir estratégias, para a intervenção imediata, no ordenamento territorial e nortear os rumos da expansão do espaço urbano, estabelecendo princípios de ação, para o conjunto dos agentes envolvidos, na construção da organização espacial municipal BRASIL, 2001).

As premissas que definiram caminhos principalmente para a elaboração de diretrizes e propostas do PDDIP (2007), foram: as condições ambientais, sítio ambientalmente frágil, configuração da cidade portuária, necessidade de expansão, consolidação da identidade e conflitos que precisam ser administrados; sendo que o PDDIP é o instrumento básico da política urbana a ser executado pelo município, e que segundo o art. 203 da Lei Orgânica n³/97 (PARANAGUÁ, 1997), deverá 
Revista Nacional de

Gerenciamento de Cidades

promover programas de saneamento básico destinados a melhorar as condições sanitárias e ambientais das áreas urbanas e os níveis de saúde da população.

A proposta do zoneamento territorial do município de Paranaguá visa dar a cada região um destino de melhor utilização, em função das condições ambientais, da topografia, de sistema viário e da infraestrutura já existente, ou que ainda será criada e, mediante a indicação do Plano Diretor de Desenvolvimento Integrado, foi criada a Lei Complementar $n^{\circ} 062 / 07$, a qual institui o atual Zoneamento do Uso e Ocupação do Solo no município de Paranaguá, dividindo o mesmo em macro zonas geográficas, a rural e a urbana, as quais apresentam-se com subdivisões em zonas e setores, conforme disposto na Lei que regulamenta $o$ Zoneamento. (PARANAGUÁ, 2007, LC 62).

Denota-se então, que o PDDIP mediante a Lei Complementar N060, de 23 de Agosto de 2007, é o instrumento legal para estabelecer objetivos e diretrizes visando a orientação e organização do crescimento da cidade. O plano diretor fixará os critérios que assegurem a função social da propriedade, cujo uso e ocupação deverá respeitar a legislação urbanística, a proteção do patrimônio ambiental natural e constituído e, o interesse da coletividade, definindo áreas especiais tais como os Setores Especiais de Adensamento (SEA) (PARANAGUÁ, 2007, LC 60).

A Lei Complementar $n^{\circ} 062 / 07$, em seu Art.61, descreve-nos que os Setores Especiais, compreendem áreas para as quais são estabelecidas ordenações especiais de uso e ocupação do solo, condicionados as suas características existentes ou projetadas e dos objetivos e diretrizes de ocupação da cidade, onde através da Figura 3, observamos sua distribuição na área urbana. Caracterizam-se segundo o Art.63 "pela existência de infraestrutura compatível com a verticalização e o adensamento populacional, configurando-se como eixo de crescimento em que se permite ocupação mista e de média e alta densidade habitacional". Objetivam proporcionar condições de infra-estutura, principalmente relacionada ao saneamento, para que ocorra a verticalização e o adensamento dos eixos 


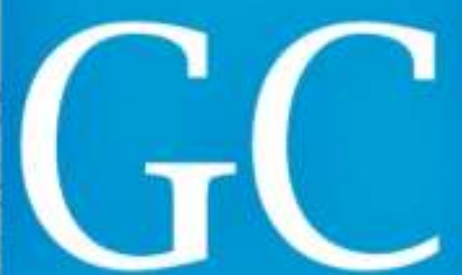

Revista Nacional de

Gerenciamento de Cidades

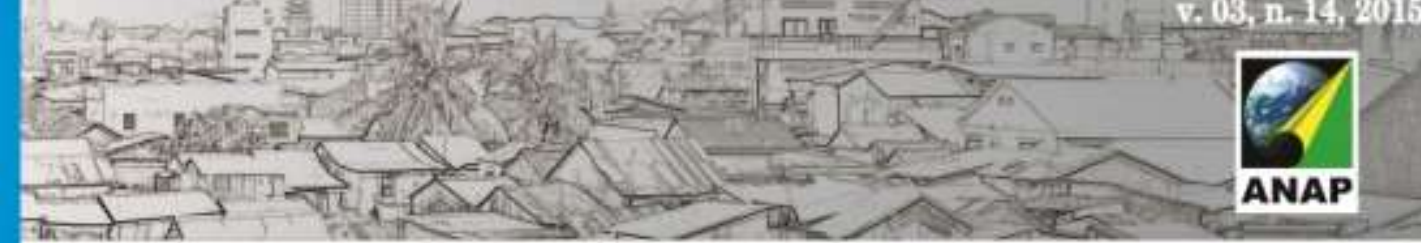

específicos, qualificando a paisagem e aproveitando a infra-estrutura existente (PARANAGUÁ, 2007, LC 62).

Setores Especiais de Adensamento propostos pelo PDDIP correspondem aos lotes com testada para as principais vias de acesso rodoviário da área urbana. As áreas marcadas com as cores verde, laranja e azul, correspondem aos Setores Especiais de Adensamento I, II e III, conforme respectivamente representados na figura 5, a seguir. Sendo possível, de acordo com o setor, construir edificações de 04 (quatro) a 12 (doze) pavimentos (PARANAGUÁ, 2007, LC 62).

Figura 3: Setores Especiais de Adensamento do Município de Paranaguá

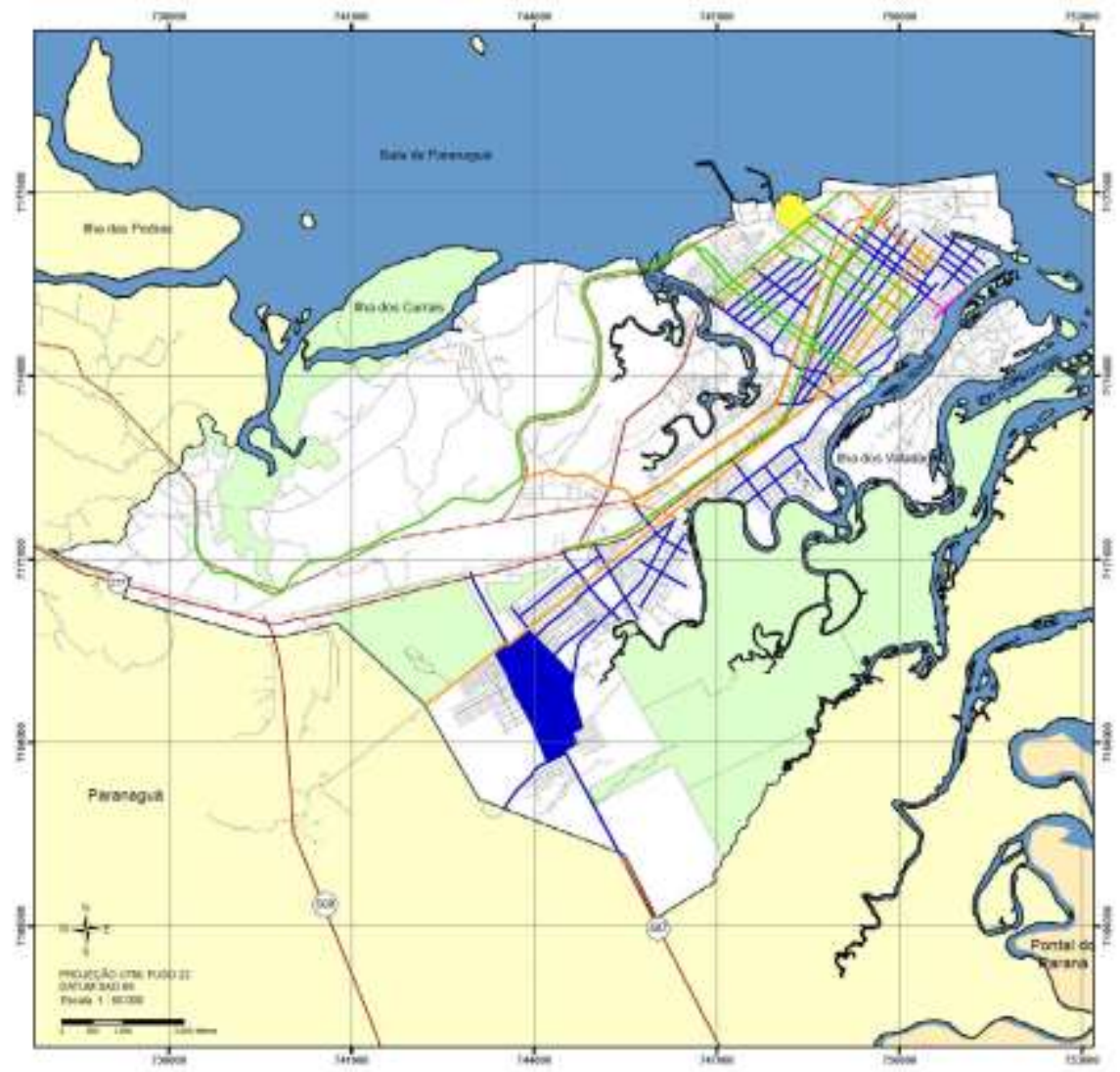

Fonte: Carta dos Setores Especiais de Adensamento do PDDIP (2007)

Desta forma, o PDDIP aponta como alternativa o Adensamento Populacional por Verticalização das edificações para atender essa demanda, nos Setores 
Revista Nacional de

Gerenciamento de Cidades

Especiais de Adensamento; os quais estão associados à infraestruturas existentes nas principais vias de acesso rodoviário urbano, onde a área urbana que concentra a maior parte dos SEA, também é a mais consolidada, como podemos verificar na Figura 3.

No entanto, o processo de edificações por verticalização nesses setores não está acontecendo, tendo como base o levantamento realizado por Tonetti (2011) que cita 17 edificações com mais de 4 pavimentos na área urbana e as verificações atuais, dos autores, "in loco", de que este número de edificações não mudou. Contudo, o número de habitantes continua aumentando, sendo esperado um incremento populacional de 9.000 habitates para os últimos cinco anos (IPARDES, 2015, p. 13).

Se a área total do Município disponível para antropização é reduzida, o processo de verticalização não está ocorrendo e a população está aumentando, então, o atendimento da demanda por novas habitações, deve estar ocorrendo de forma horizontal, possivelmente, ocupando os manguezais e as margens de rios, com edificações e outras construções desordenadas e irregulares, comprometendo também a qualidade do ambiente urbanizado e a melhoria da qualidade de vida do cidadão.

\subsection{EXPANSÃO URBANA HORIZONTAL SOBRE MANGUEZAL: O CASO DOS BAIRROS JARDIM IGUAÇU E VILA MARINHO}

Os bairros, Jardim Iguaçu e Vila Marinho, escolhidos para evidenciar a existência, ainda hoje, da expansão urbana horizontal em Paranaguá, representam bem as características a serem descritas para toda a área urbana do município.

Conforme a Figura 4 (foto aérea), pode-se verificar que no ano de 1980, neste local de estudo, não havia ação antrópica relacionada á construções de moradias (habitações), onde o acesso a esse local era apenas via "estrada de chão", isto é, acesso sem nenhuma pavimentação e totalmente desprovido de benfeitorias, 


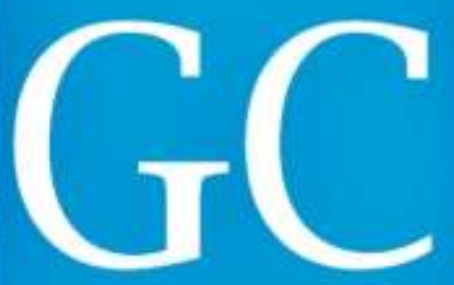

Revista Nacional de

Gerenciamento de Cidades

no sentido sul, e aos sentidos norte, leste e oeste, a região era circundada pelo Rio Emboguaçu, por áreas de manguezais e por vegetação caracterizada por Ombrófila Densa de Terras Baixas.

Figura 4: Foto aérea da área de estudo, demarcada o seu contorno por cor vermelha

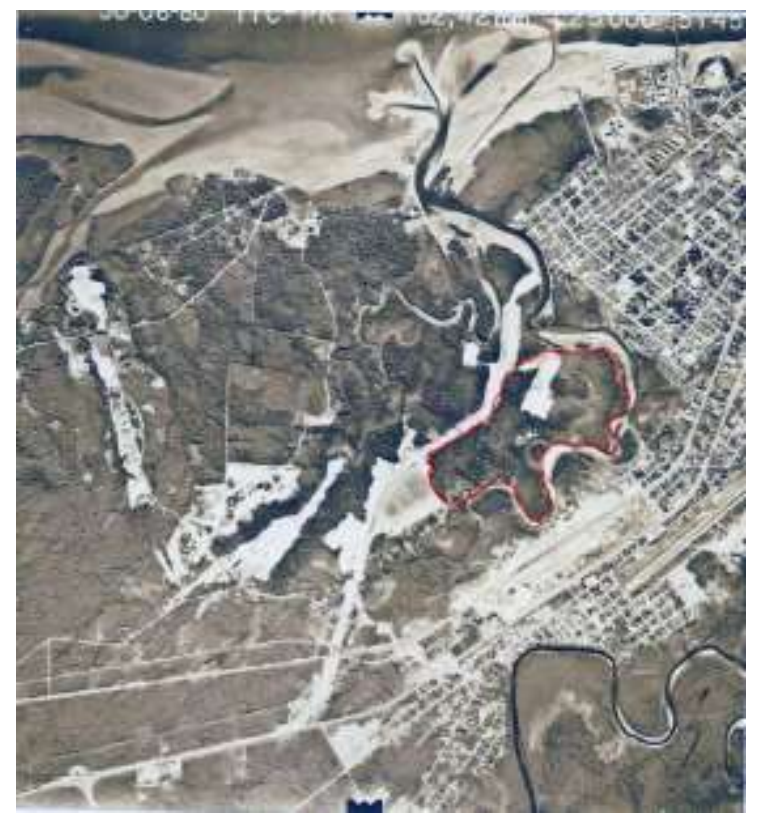

Fonte: Instituto de Terras e Cartografia- PR (1980)

De acordo com a figura 4, percebe-se que a área de estudo, em 1980, não possuía nenhuma habitação. A ocupação irregular e desordenada, nos bairros Jardim Iguaçu e Vila Marinho, iniciou-se em meados do ano de 1995, precisamente frente a atual variante da $\mathrm{Br} 277$, com o corte da vegetação nativa, implantação de caminhos de acesso aos lotes e às delimitações realizadas por cercas de arame, cordas ou palanques de madeira extraídos do próprio corte da vegetação.

Esta atividade no início foi coibida pela ação fiscalizatória do Instituto Ambiental do Paraná (IAP), o qual lavrou auto de infração ambiental e embargou as atividades referentes ao corte de vegetação. Porém, com a construção da ponte sobre o Rio Emboguaçu, e em função da defasagem do quadro funcional dos órgãos ambientais, a fiscalização ostensiva reduziu-se, onde o processo de ocupação 
Revista Nacional de

Gerenciamento de Cidades

desordenada e irregular, avançou ainda mais sobre as APPs, com aterros e supressão da vegetação.

Iniciaram-se então as construções de habitações, as especulações imobiliárias, as perfurações de poços artesianos para o consumo de água e no decorrer dos anos, a consequente implantação da infraestrutura urbana, ganhando então a denominação de "bairros".

Com a pavimentação (asfalto) da então "estrada de chão", atual variante da BR 277, as imediações também foram se consolidando, com a instalação de mais dois bairros sendo a Vila Santa Helena e a Vila Figueira, ambos também com ocupações desordenadas e irregulares afetando também os manguezais.

Hoje, nas adjacências há um Posto de Abastecimento de Combustível, uma Estação de Tratamento de Esgoto da empresa Águas de Paranaguá, Pátios para estacionamentos de caminhões e containeres, empresas ligadas ao transporte e armazenamento de fertilizantes como as Empresas Fertipar e Tranzella, sendo que esta variante da $\mathrm{Br} 277$ é a principal via municipal de acesso até o Porto de Paranaguá, utilizada principalmente pelos caminhões que escoam a produção agrícola do Estado.

A área de estudo Jardim Iguaçu e Vila Marinho, segundo o Zoneamento Urbano inserem-se na Zona de Consolidação e Qualificação Urbana Três (ZCQU 3). Nesse sentido, esses bairros caracterizam-se por possuir áreas consolidadas regulares e irregulares, áreas passíveis de ocupação e áreas ambientalmente degradadas. Também, de acordo com esse zoneamento, existe a necessidade de promover a ocupação ordenada do território, qualificar a paisagem, implantar novos usos e utilidades, principalmente o habitacional, ampliar a disponibilidade de equipamentos e serviços públicos, ampliar a oferta de infraestrutura, de forma a possibilitar a ocupação do território e promover a recuperação do meio ambiente. (PARANAGUÁ, 2007, LC 62). Por esse motivo, esses bairros, passam por um processo de urbanização junto a um projeto dos governos Estadual e Municipal, afim de regularização fundiária. 


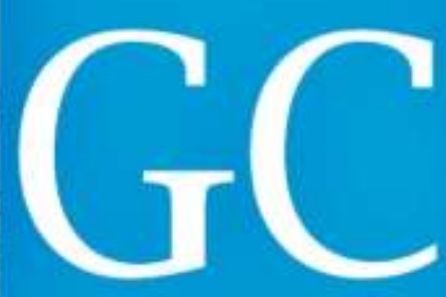

Revista Nacional de Gerenciamento de Cidades

Atualmente, essas áreas consolidam-se precariamente devido as ocupações e construções desordenadas, falta de saneamento básico, pavimentação, coleta de lixo, áreas de lazer, entre outras, embora haja nesse local escola, posto de saúde, pontos de comércio e acesso parcialmente asfaltado ao transporte coletivo de ônibus municipal.

$\mathrm{Na}$ imagem de satélite de 2010 (Figura 5) e na foto (Figura 6), observa-se a configuração atual do uso do solo nos bairros, onde se constata visualmente inúmeras habitações e arruamentos adentrando o manguezal.

Figura 5: Imagem de satélite dos bairros Jardim Iguaçu (circundado pela cor vermelha) e Vila Marinho (circundado pela cor azul)

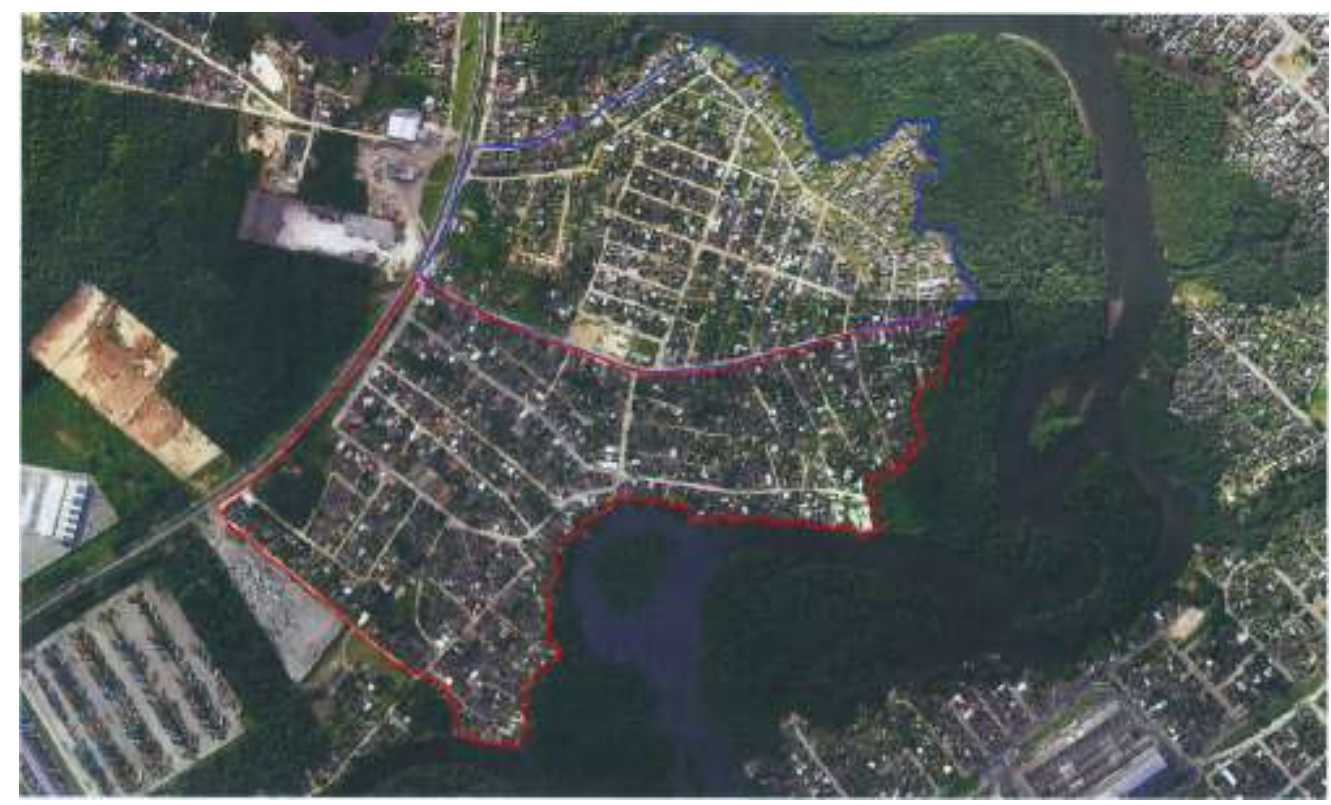

FONTE: Prefeitura Municipal de Paranaguá (2010) 


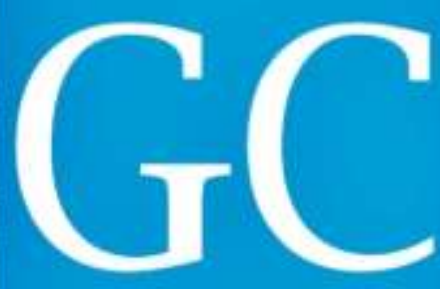

Revista Nacional de

Gerenciamento de Cidades

Figura 6: Avanço do arruamento e habitações sobre o manguezal no bairro Jardim Iguaçu

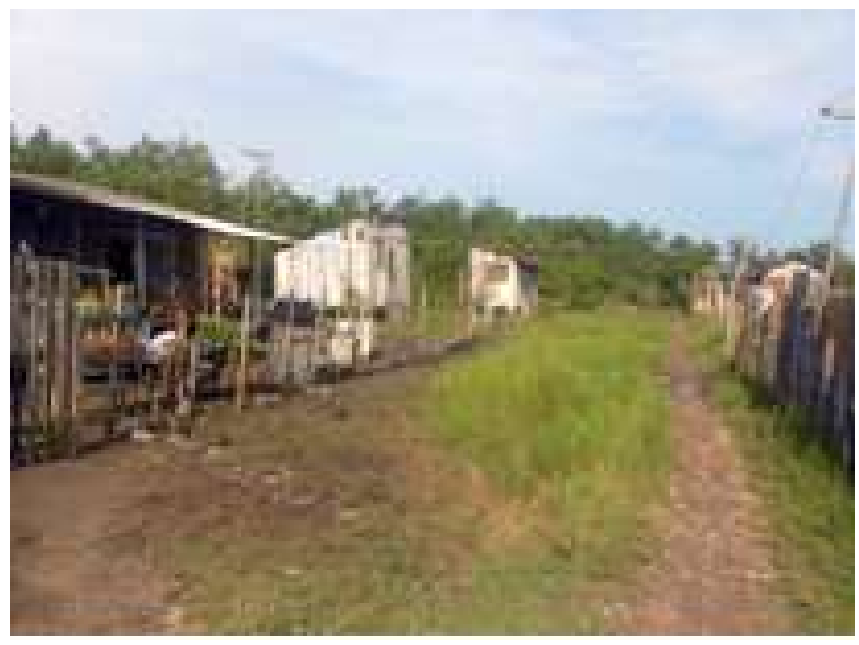

Fonte: Os autores (2013)

As famílias inseridas além dos limites da preamar média do local de estudo, onde se constata o avanço recente das ocupações irregulares sobre os terrenos da União, como representada pela Figura 6, serão realocadas, após ações do Ministério Público, para habitações do programa Morar Bem Paraná, em fase de construção no bairro Moradias Porto Seguro. O projeto está sendo desenvolvido pela Prefeitura Municipal de Paranaguá, tendo como contribuintes o Instituto Ambiental do Paraná (IAP), o IBAMA (instituto Brasileiro do Meio Ambiente e Recursos Naturais Renováveis), a Copel (Companhia Paranaense de Enegia Elétrica) e o Colit (Conselho do Litoral Paranaense).

Esta intervenção é um caso particular dentre inúmeros bairros, em condições irregulares semelhantes, presentes na área urbana de Paranaguá. Contudo, esta ação pode sinalizar um novo rumo do planejamento urbano do Município.

No entanto, em detrimento das estratégias do PDDIP, o referido projeto de moradias não prevê a verticalização das edificações. Desta forma, perde-se a oportunidade de instaurar as orientações do ordenamento territorial e nortear os rumos da expansão do espaço urbano. 
Revista Nacional de

Gerenciamento de Cidades

Desta forma, a expansão urbana, hoje, ocorre horizontalmente, de forma regularizada, dentro das áreas previstas para a instalação de novas moradias, e de forma irregular sobre as áreas de manguezais e margens de rios. São diversos os bairros em Paranaguá que apresentam um grande número de ocupações irregulares e desordenadas, basta transitar pelos bairros vizinhos aos de estudo, como: Vila Santa Helena, Vila Figueira, Padre Jackson, Beira Rio, Emboguaçu, Vila do Povo e Vila Primavera, para se perceber que ainda ocorre constante supressão da vegetação, aterro e edificações sobre o manguezal, em detrimento da verticalização dos SEA.

\section{CONSIDERAÇÕES FINAIS}

Este estudo discutiu a perda das áreas de Formação Pioneiras sob Influência Fluviomarinha (manguezal), no município de Paranaguá no litoral do Paraná.

Os textos revisados demonstram que no processo histórico de expansão da área e no crescimento populacional urbano do município de Paranaguá houve influência dos ciclos econômicos do Estado do Paraná, assim como, da presença de um Porto no município. Tais características, culminaram em um crescimento acelerado e desordenado horizontalmente, afetando ambientes frágeis, como as áreas de manguezais e beiras de rios, áreas essas que, segundo a legislação ambiental, são consideradas de Preservação Permanente.

Apesar da atual orientação do Plano Diretor de Desenvolvimento Integrado para realizar o adensamento populacional por verticalização das edificações, como ferramenta para ordenar o território e encaminhar os rumos da expansão do espaço urbano, o município de Paranaguá ainda não conseguiu implantar tal adensamento, permanecendo a influência do crescimento histórico - horizontalizado - até os dias de hoje. 
Revista Nacional de

Gerenciamento de Cidades

Nota-se através deste trabalho, que o crescimento urbano populacional nos casos estudados vem ocorrendo e expandindo-se horizontalmente sobre os manguezais, de forma irregular e desordenada, o que afronta, em situações limites, a legislação ambiental. Os resultados sinalizam que o mesmo processo deve estar ocorrendo em toda área urbana do município de Paranaguá.

\section{REFERÊNCIAS}

APPA. Administração dos Portos de Paranaguá e Antonina. Levantamento da situação atual do Poto de Paranaguá, Governo do Estado do Paraná,1994. Disponível em: http://www.appa.pr.gov.br . Acesso em: 12 jun. 2013.

BRASIL. Decreto $n^{\circ} 24.643$ de 10 de julho de 1934. Decreta o códico de águas. Diário Oficial da União da República Federativa do Brasil, Rio de Janeiro, RJ, v.4, p. 679, 20 jul. Seção 1.

Disponível em: <w.w.w.jusbrasil.com.br/.../art - 11 do código - de- aguas- decreto - 24643 - 34>. Acesso em: 22 mai. 2013.

BRASIL. Resolução CONAMA, $n^{\circ}$ 04, de18 de setembro de 1985. Diário Oficial da União da República Federativa do Brasil, Brasília, 20 jan. 1986. Disponível em:

<w.w.w.mma.gov.br/pot/conama/res/res85/res0485.html>. Acesso em: 20 mar. 2013.

BRASIL. Lei $\mathrm{n}^{\circ} 7661$ de 16 de maio de 1998a. Institui o Plano Nacional de Gerenciamento Costeiro e dá outras providências. Diário Oficial da União da República Federativa do Brasil, Brasília, 18 mai. 1998. Disponível em: <w.w.w.jusbrasil.com.br/legislacao/anotada/2696891/lei-7661-88>. Acesso em: 26 mar. 2013.

BRASIL. Lei no 9.605 de 12 de fevereiro de 1998b. Dispõe sobre as sanções penais e administrativas derivadas de condutas e atividades lesivas ao meio ambiente, e dá outras providências. Diário Oficial da União da República Federativa do Brasil, Brasília, 13 fev. 1998. Disponível em:

$<$ http://www.unmp.org.br/index.php?option=com_content\&view=article\&id=94:lei-9605-98-crimesambientais\&catid=37:lei-federal\&ltemid $=96>$.

Acesso em: 20 mar. 2013.

BRASIL. Lei n 10257 de 10 de julho de 2001. Regulamenta os arts. 182 e 183 da Constituição Federal, estabelece diretrizes gerais da política urbana e dá outras providências. Diário Oficial da União da República Federativa do Brasil, Brasília, 17 jul. 2001. Disponível em:

<w.w.w.planalto.gov.br/ccvil 03/leis?LEIS 2001/L 10257.htm>. Acesso em: 30 abr. 2013.

BRASIL. Resolução CONAMA, n 303, de 20 de março de 2002. Dispõe sobre parâmetros, definições e limites de Áreas de Preservação Permanente. Diário Oficial da União da República Federativa do Brasil, Brasília, 13 mai. 2002.Disponível em:

<w.w.w.mma.gov.br/port/conama/legiabre.cfm?codlegi=299>. Acesso em: 22 mar. 2013.

BRASIL. Lei $n^{\circ} 12651$ de 25 de maio de 2012. Dispõe sobre a proteção da vegetação nativa; altera as Leis nos 6.938, de 31 de agosto de 1981, 9.393, de 19 de dezembro de 1996, e 11.428, de 22 de dezembro de 2006; revoga as Leis nos 4.771, de 15 de setembro de 1965, e 7.754, de 14 de abril de 
1989, e a Medida Provisória no 2.166-67, de 24 de agosto de 2001; e dá outras providências. Diário Oficial da União da República Federativa do Brasil, Brasília, 28 mai. 2012. Disponível em: <w.w.w.jusbrasil.com.br/legislação/1032082/lei _12651-12>. Acesso em: 16 mar. 2013.

CANEPARO, S. C. Manguezais de Paranaguá uma análise da dinâmica espacial da ocupação antrópica - 1952-1996. 289 f. Tese (Doutorado em Meio Ambiente e Desenvolvimento). Universidade Federal do Paraná. Curitiba, 1999.

ESTADES, N. P. O Litoral do Paraná: entre a riqueza natural e a pobreza social. In: Desenvolvimento e meio ambiente. Dinâmicas naturais dos ambientes costeiros: usos e conflitos. Curitiba: Ed. UFPR, 2003. p. $26-41$.

GODOY, A. M. G. Os impactos socioambientais na expansão do porto de Paranaguá frente à maior inserção do Brasil no mercado internacional. In: Meio ambiente e desenvolvimento no litoral do Paraná: diagnóstico. Curitiba: UFPR, 1998. p. 231-235.

IBGE - Instituto Brasileiro de Geografia e Estatística. Censo Demográfico de 2011. Disponível em: <http:// w.w.w. SIDRA.IBGE.gov.br>. Acesso em: 17 jul. 2013.

IPARDES. Instituto Paranaense de Desenvolvimento Econômico e Social. Caderno Estatístico do Município de Paranaguá-PR. 2015, 42p. Disponível em:

http://www.ipardes.gov.br/cadernos/MontaCadPdf1.php?Municipio=83200

Acesso em: 22 abr. 2015.

PARANAGUÁ. Lei Orgânica do Município de Paranaguá nº 03, de 03 de setembro de 1997. Disponível em: w.w.w.leismunicipais.com.br/lm/leis-organica/paranagua-pr/3400.html\&prefeitura-1. Acesso em: 12 abr. 2013.

PARANAGUÁ. Lei Complementar nº60, de 23 de agosto de 2007. Institui o Plano Diretor de Desenvolvimento Integrado, estabelece objetivos, instrumentos e diretrizes para as ações de planejamento no Município de Paranaguá e dá outras providências. Disponível em http://www.helts.com.br/paranagua/plano_diretor.php. Acesso em: 09 abr. 2013.

PARANAGUÁ. Lei Complementar n 062, de 27 de agosto de 2007. Institui o Zoneamento de Uso e Ocupação do Solo. Disponível em:

w.w.w.colit.pr.gov.br/arquivos/file/analises_Planos_Diretores/paranagua_25_06_2009_26_11_2010_s intese.pdf. Acesso em: 09 abr. 2013.

PDDIP - Plano Diretor de Desenvolvimento Integrado de Paranaguá. Estabelece objetivos, instrumentos e diretrizes para as ações de planejamento no Município de Paranaguá, 2007. Disponível em: w.w.w.paranagua.gov.br/plano-diretor/LEICOMPLEMENTAR_NO60-

PLANO DIRETOR-NOVO.pdf. Acesso em: 04 abr. 2013.

RICOBOM, A. E. Metodologia Auxiliar para Revisão de Planos Diretores Municipais através da Aplicação da Cartografia Prospectiva. $511 \mathrm{f}$. Tese (Doutorado em Geografia) - Setor de Ciências da Terra, Universidade Federal do Paraná, Curitiba, 2012.

SANTOS, A. V. Memória histórica da cidade de Paranaguá e seu município. 3. ed. Paranaguá: Câmara Municipal, 1952. v. 1. 


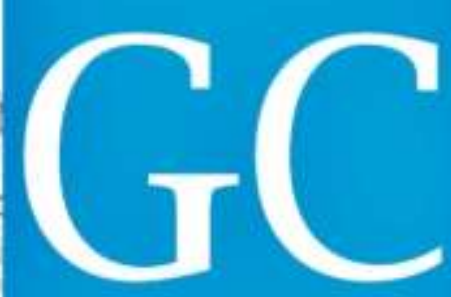

Revista Nacional de

TONETTI, E. L. Pontencialidades de Adensamento Populacional por Verticalização das Edificações e Qualidade Ambiental Urbana no Município de Paranaguá. 235 p. Tese (Doutorado em Geografia) - Setor de Ciências da Terra, Universidade Federal do Paraná, Curitiba, 2011.

TONETTI, E. L.; NUCCI, J. C.; VALASK, S. Espaços Livres na Área Urbana de Paranaguá. Revsbau, Piracicaba, v.7, n.2, pp. 37 - 50, 2012. Disponível em: <w.w.w.Revsbau.esalq.usp.br>. Acesso em: 23 abr. 2013.

TRAMUJAS, A. Histórias de Paranaguá - dos pioneiros da Cotinga à porta do Mercosul no Brasil Meridional. Paranaguá: Prefeitura Municipal de Paranaguá, 1996. 180 p. 